\title{
LOS CONCEPTOS DE MODELO Y EJEMPLO DE VERSO, Y DE EJECUCIÓN
}

José Domínguez Caparrós

$U N E D$

Los conceptos de modelo y ejemplo de verso, en cuanto que son asimilables a los de metro (norma abstracta) y ritmo (manifestación real del verso), pueden considerarse tradicionales en la teoría métrica. De las relaciones entre el esquema abstracto que refleja un sistema de regularidades (metro) y la sucesión concreta de elementos engendrada en la realidad del verso, se han ocupado los formalistas rusos, por citar a la escuela que es un hito de la teoría literaria del siglo xx. No me voy a detener en lo que Tomachevski o Tinianov dicen al respecto, y solamente voy a referirme a Żirmunskij, quien, en su Introduction to metrics, considera el problema de las relaciones entre metro y ritmo como la cuestión fundamental de la métrica. El ritmo es, para Żirmunskij, la alternancia real de los acentos en el verso (Žirmunskij está hablando de un sistema acentual o silabotónico de versificación, como es el ruso), que resulta de la interacción de las propiedades inherentes del material lingüístico y la norma ideal impuesta por el metro. Las relaciones no pueden quedar mejor establecidas que en las mismas palabras de Zirmunskij [1925:12]:

La ley que regula la alternancia de sonidos acentuados y no acentuados puede expresarse en un esquema ideal (metro). El medio lingüístico, sin embargo, tiene sus propias características fonéticas naturales, independientes de la ley métrica, y entonces el medio lingüístico ofrece resistencia al esquema métrico. En este sentido, el ritmo poético resulta de la interacción del esquema métrico con las propiedades fonéticas naturales del material verbal'.

1 La traducción del inglés del texto citado es mía. El pensamiento de Tinianov sobre esta cuestión, en 1924:31; y el de Tomachevski, en 1929:157 y 166. 
Un ejemplo, tomado de la versificación castellana, ilustrará los conceptos de forma práctica, y ayudará a la adhesión al pensamiento de Žirmunskij cuando considera este problema la cuestión central de la métrica. El alejandrino anapéstico (que Navarro Tomás, de acuerdo con su sistema de análisis del verso, llama alejandrino dactílico) se define como el verso de catorce sílabas métricas, compuesto de dos hemistiquios heptasílabos que llevan acento en las sílabas tercera y sexta. La definición dada coincide con lo que entendemos por metro de dicho verso. Ejemplo de alejandrino anapéstico son los conocidos versos de Rubén Darío:

La princesa está triste. ¿Qué tendrá la princesa?

Los suspiros se escapan de su boca de fresa que ha perdido la risa, que ha perdido el color.

Estos versos, aun ajustándose todos al metro del alejandrino anapéstico, presentan un movimiento rítmico diferente (en virtud de la manifestación lingüística concreta), que se puede ilustrar comparando el esquema acentual del metro (ooóooóo : ooóooóo) con el esquema acentual concreto de cada uno de ellos (ooóoóó : óoóooóo; ooóooóo : oobooóo; óóooóo : 6oboobo). Los versos primero y tercero tienen un ritmo acentual que contrasta con el ritmo, ajustado al metro, del segundo $^{2}$. Pueden apreciarse, entre las variaciones rítmicas del verso, muchos otros aspectos estilísticos que entran en una consideración amplia del ritmo (repeticiones sonoras de distintas clases o paralelismo, por ejemplo), y que, sin duda, influyen en que un verso sea distinto de su vecino, a pesar de la común referencia al metro a que pertenecen. No nos puede extrañar que la cuestión de aislar unas constantes, a las que obedece el poeta en su ordenación del material lingüístico y el lector en su percepción del ritmo, es la preocupación central de la métrica. Esto ha sido así en los mejores trabajos del pasado sobre el verso, $\mathrm{y}$ en las escuelas que en el siglo $\mathrm{xx}$ se han inspirado en los desarrollos de la lingüística.

Por ejemplo, Andrés Bello [1859:144], que puede ser considerado el fundador de la métrica castellana moderna, diferencia, en función de un esquema o patrón rítmico acentual, lo que es fundamental y lo que es accesorio, cuando dice:

2 Para la definición del alejandrino, véase José Domínguez Caparrós, 1985:s.v. alejandrino anapéstico. 
De aquí [de la monotonía que se derivaría de la aparición de todos los acentos exigidos por el esquema] es que en los versos trocaicos y yámbicos que no pasan de ocho sílabas y que no se destinan al canto, no se somete el poeta a la necesidad de otro acento que el de la cláusula final, y acentúa las otras como quiere; de que resultan unas veces acentos rítmicos, esto es colocados en las sílabas impares de los versos trocaicos y en las sílabas pares de los yámbicos, y otras veces acentos accidentales o antirritmicos, esto es, colocados en los parajes del verso que no piden acento.

Mario Fubini [1962:38], al referirse al ritmo como el encuentro del elemento variable y el elemento constante, o Navarro Tomás [1956:27] cuando habla de "unidades abstractas que se realizan en la práctica bajo modalidades de distinto efecto sonoro", no hacen más que tener en cuenta la existencia del modelo, del esquema, como realidad distinta de la manifestación lingüística concreta del verso ${ }^{3}$.

Podrían añadirse algunas observaciones más en este sentido, pero voy a terminar con la mención del paralelismo que se hace entre los conceptos de metro y ritmo con conceptos fundamentales de las dos corrientes lingüísticas que han llenado prácticamente el siglo XX: el estructuralismo y la lingüística generativa. Ilustro el paralelismo entre modelo y ejemplo de verso, por un lado, y los conceptos estructuralistas de lengua y habla, por el otro, con las palabras de Hernández Vista [1972:96], cuando señala como una de las bases de su concepción del ritmo:

Que el fenómeno rítmico es también un fenómeno a dos caras, abstracta la una, concreta o de realización la otra, tal como R. Jakobson ha explicado, reduciéndolo en última instancia al binomio lengua / habla de Saussure: y en su reducción está la originalidad y perspicacia de Jakobson 4 .

3 Manifestaciones de la distinción de un aspecto abstracto y otro concreto, pueden encontrarse también en Benjamin Hrushovski, 1960:178-179; Costanzo di Girolamo, 1983:2223. Lowry Nelson, Jr. [1972:168-169], por ejemplo, dice: "The actualized phonic effect of the counterpoint between the meter and a given line is the rhythm. Even if the given line departs notably from the ideal meter, it must still be read (or better. performed) with the ideal meter in mind and not as a prose".

4 Sobre esta cuestión, puede verse también Mario Fubini [1962:13]; H. Jacquier [1970:122]; Sebastián Mariner Bigorra [1971:310-311]. 
La distinción, considerada fundamental por Morris Halle [1970:64], entre metro (esquema de entidades abstractas) y actualización (del metro en secuencias concretas de palabras) es puesta en relación con la competencia y la actuación, respectivamente, por Jacqueline Guéron, por ejemplo [1974:94].

Aunque se critica el establecimiento de estas relaciones [Ihwe, 1975:391; Benoît de Cornulier, 1982:39], tampoco falta la indicación del parentesco que en este punto une a la métrica generativa con la métrica tradicional. Dice J.C. Beaver [1974:8]:

\begin{abstract}
All current versions of generative metrics (and indeed of most forms of traditional metrics) assume the reality of an abstract metrical pattern, which is concretized by an arrangement of linguistic material to fit this pattern.
\end{abstract}

Jakobson amplía el cuadro de estos conceptos en el trabajo que es considerado como el manifiesto fundacional de la poética estructuralista: Lingüística y poética, 1960. En efecto, allí [Jakobson, 1960:229-233] se definen e ilustran con ejemplos los conceptos de modelo de verso (verse design), ejemplo de verso (verse instance), modelo de ejecución (delivery design) y ejemplo de ejecución (delivery instance). Los conceptos de modelo y ejemplo de verso enlazan con las observaciones hechas por la métrica tradicional, los formalistas rusos o las más modernas métrica estructural y métrica generativa sobre la existencia de elementos abstractos, constantes, esquemáticos, que están presentes en las manifestaciones lingüísticas del verso. Un verso concreto es un ejemplo de verso, regido por un modelo de verso, que determina las invariantes y fija los límites de las variaciones. Modelo y ejemplo de verso se sitúan en el terreno de la producción y manifestación lingüística del texto, y sólo indirectamente (en cuanto que el receptor debe conocer o percibir, en el proceso de la lectura, el modelo de verso, para poder captar correctamente el texto versificado) se relacionan con la recepción. Aunque no hubiera recepción de un texto, teóricamente seguiría existiendo el modelo y el ejemplo de verso.

Sin embargo, los conceptos de modelo y ejemplo de ejecución se sitúan plena y exclusivamente en el terreno de la recepción. El ejemplo de ejecución de un verso es la interpretación concreta hecha por un lector, un recitador de dicho verso. Esta interpretación depende del modelo de ejecución que adopta el receptor, quien puede oscilar entre los extremos marcados por un estilo, un modelo, estrictamente rítmico (tendente a poner de manifiesto la escansión de los elementos rítmi- 
cos) y un modelo cercano a la prosodia de la prosa. Los versos de Rubén Darío ya comentados pueden servir de ejemplo. En efecto, el verso primero, si el recitador adopta un modelo de ejecución rítmico -y en el caso concreto, el modelo de ejecución rítmico del alejandrino anapéstico-, desacentuará el verbo está y él interrogativo qué, por no ocupar posición acentual exigida por el modelo de verso $\mathrm{Si}$, por el contrario, el receptor toma como modelo de ejecución el de la prosodia de la prosa, en el ejemplo de ejecución (es decir, en la recitación concreta) aparecerán acentuadas esas sílabas. Lo mismo ocurrirá con la acentuación o desacentuación de la forma verbal ha en las dos ocasiones en que aparece en el verso tercero. El verso segundo, sin embargo, es totalmente estable en cuanto al ritmo acentual, y, se adopte el modelo de ejecución que se adopte, siempre se acentuarán las mismas sílabas (coinciden, pues, esquema acentual y acentuación gramatical). El comentario puede extenderse a otros aspectos del ritmo como, por ejemplo, la pausa; pero precisamente a fenómenos que tienen que ver con la pausa está dedicada la segunda parte del presente trabajo, y por eso no alargo ahora mis apreciaciones.

Si la discusión sobre los conceptos de modelo y ejemplo de verso se relaciona con la tradicional apreciación de constantes y variables, la de los conceptos de modelo y ejemplo de ejecución se relaciona con la posibilidad de distintas interpretaciones, recepciones, del verso. $Y$ este hecho ha estado presente en grandes tratadistas, que pueden ser adscritos a la métrica tradicional, como Julio Saavedra Molina, cuando dice, por ejemplo [1945:32]:

Porque voy a repetirlo: el verso no es la cosa rígida y congelada que describen los metricistas, sino la creación fugaz durante la audición de quien percibe el verso. No son raros, pues, los versos escritos que admiten dos o más lecturas, dos o más acentuaciones o interpretaciones rítmicas

Gian Luigi Beccaria se ha ocupado, en unas atinadas páginas, de la importancia relativa que tiene la variedad de lecturas de un verso, de las relaciones entre recepción y metro, de la posibilidad de actitudes

5 Julio Saavedra Molina insiste frecuentemente en la importancia de la recepción. Asf, cuando dice [1950:52]: "Nos enseña también aquel distingo entre letra y voz que el valor de un escrito depende de su capacidad intrínseca para provocar una interpretación adecuada del lector, interpretación que, en definitiva, será el verdadero poema; pudiendo, en consecuencia, coexistir tantas interpretaciones distintas y adecuadas como lectores; 0 sea, muchos poemas auditivos por cada poema escrito". 
lectoras diferentes -tendencia ritmizante o tendencia a respetar la frase, por ejemplo-, con referencias continuas a los mejores tratadistas del ritmo y del verso, para terminar [1975:21]:

Concludendo: se per noi la poesia è artefatto e scritura letteraria (indirizzata pertanto ad una lettura silenziosa), il metro o el ritmo non vanno identificati né dedotti dalla esecuzione; tutto ciò che un lettore, recitando o leggendo una poesia, introduce, non va considerato come una proprietà del componimento in questione. Pud variare benissimo il tempo nella dizione di un verso, ma il rapporto delle parti fra loro resta invariato".

Antes de pasar a la segunda parte de este trabajo, en la que trataré de ver qué aplicación pueden tener estos conceptos en el estudio del encabalgamiento, quiero solamente mencionar algunos autores, espanoles o relacionados con la métrica española, que han tenido en cuenta algunos de los conceptos teóricos objeto de definición aquí. Sebastián Mariner Bigorra [1971:308, 310-311] alude a los conceptos de Jakobson, pero le interesa resaltar solamente la oposición entre estructura y realización; por eso ni siquiera menciona el concepto de modelo de ejecución, y establece la oposición entre modelo y ejemplo de verso, por un lado, y ejemplo de ejecución, por el otro.

También V. Eugenio Hernández Vista [1972:104] se refiere a los conceptos de Jakobson, pero, como Mariner Bigorra, resalta la oposición estructura-realización y no menciona tampoco el concepto de modelo de ejecución, que, sin embargo, considero fundamental, pues es el que, en última instancia, da la clave de las distintas interpretaciones por parte del receptor, según espero ilustrar en la segunda parte de este trabajo. Fernando Lázaro Carreter [1972: 81, especialmente] invoca la autoridad de Roman Jakobson cuando define los conceptos de modelo de verso y realización de verso, que utiliza ampliamente en su análisis del verso de arte mayor, y no presta atención, sin embargo, a los otros dos conceptos (modelo y ejemplo de ejecución).

Oldrich Bèlič [1975:15,83,94,98-99], en el contexto de su continua referencia a la versología eslava, a la hora de comentar la naturaleza

${ }^{6}$ Para todas estas cuestiones son interesantes las páginas 13-21. En la nota 53, de la pág. 19, hay una referencia a los conceptos de Jakobson que he comentado. La objeción de Beccaria a Jakobson, con que termina la nota, y que consiste en decir que el metro tiene caracteres de ambigüedad y equívocos, parece denotar una incomprensión del concepto jakobsoniano, que no es un concepto normativo sino abstracto, general. 
del verso español, tiene también en cuenta los conceptos de norma rítmica y ritmo concreto, pero no se refiere a unos conceptos similares a los que se sitúan en el terreno de la recepción (modelo y ejemplo de ejecución). Aunque roza las realidades referidas con dichos conceptos, cuando trata de la escansión o de las distintas interpretaciones dadas a unos mismos versos.

Jesús Luque Moreno [1984] olvida -lo mismo que Hernández Vista y Sebastían Mariner- el modelo de ejecución, cuando analiza estos conceptos con explícita referencia al cuadro de Jakobson para el modelo de verso -nivel en el que sitúa el sistema (forma y estructura)- y para el ejemplo de verso - nivel al que asocia la composición-. Pero no hace ninguna alusión a los conceptos de Jakobson cuando trata de la realización -el cuarto de los niveles por él diferenciados-, nivel que corresponde con lo que es el ejemplo de ejecución en terminología jakobsoniana.

La conclusión, pues, de esta primera parte es que el cuadro conceptual propuesto por Jakobson es, sin duda, el más completo y el que mejor puede dar cuenta, de forma sistemática, de todos los hechos que entran en el juego del funcionamiento del verso, tanto en su aspecto productivo como en su aspecto textual y receptivo. Una de las cuestiones más polémicas, entre las que se relacionan con la pausa, nos va a servir de base en la demostración de la utilidad de los conceptos jakobsonianos. Se trata del encabalgamiento.

La cuestión del encabalgamiento se integra en la más general de la segmentación que el discurso versificado practica como característica que lo diferencia de la segmentación que se hace en la prosa, aunque ocasionalmente puedan coincidir. En principio, y como norma general -que puede ser matizada según las escuelas o las épocas- hay que afirmar que una peculiaridad del lenguaje versificado consiste en su mayor libertad de segmentación, determinada por el papel dominante que en este tipo de discurso desempaña el ritmo. Boris Tomachevski [1928:107] lo dijo con palabras nítidas:

El verso se contrapone claramente a la prosa, porque en esta última el ritmo es el resultado de la estructura semántica y formal del discurso, mientras que en el verso el ritmo es el aspecto que determina la estructura, $y$, en el ámbito del ritmo, vuelven a encontrarse significado y forma. Si después el ritmo natural del discurso coincide con los límites de la división en versos, no se trata más que de una motivación del ritmo. Pero, en general, la división del discurso en versos se produce independientemente de la segmentación natural del discurso en cola sintácticos. En los versos, el ritmo está previamente fijado, y a él se subordina la forma que, naturalmente, cambia, se deforma. 
De aquí la existencia de una sintaxis rítmica, en que la ordenación de las palabras viene determinada por la sintaxis de la lengua común, y por exigencias rítmicas. El verso, grupo primordial de palabras, es una combinación rítmica y sintáctica al mismo tiempo [Brik, 1927:148149].

Estos dos aspectos quedan perfectamente recogidos en el pensamiento de Bello [1859:131] sobre la pausa, cuando sostiene que es mejor "que la cantidad o duración de las pausas métricas coincida con la que damos naturalmente a las pausas gramaticales; mas en una obra larga no se exige la rigorosa observancia de esta regla; antes conviene de cuando en cuando apartarse de ella, para evitar el fastidio de la uniformidad y monotonía"'. Relación dinámica entre gramática (sintaxis) y ritmo, y situación del encabalgamiento entre los fenómenos que tienen que ver con lo estilístico ("para evitar el fastidio de la uniformidad y monotonía"), tales son las ideas esenciales del pensamiento de Bello en este punto. No precisa Bello cuáles son los "grupos naturales que forman como palabras compuestas en que el oído percibe un solo acento lleno" y que serían los afectados por lo que conocemos como encabalgamiento. Los ejemplos que él da consisten en la separación de adjetivo y sustantivo, adjetivo y adjetivo ("vendrá la temerosa I desventurada noche"), pronombre relativo y verbo del que es sujeto ("...que / ha de pesarte”).

Es obvio que el espacio de un artículo no es el apropiado para resumir y plantear todas las cuestiones que tienen que ver con el encabalgamiento, tanto en su aspecto teórico como en el del uso que de él se ha hecho en poesía. Hay trabajos que han resumido y tratado estos problemas en lo referente a la métrica española ${ }^{8}$. Sólo me interesa ilustrar cómo algunos de los problemas relativos a la definición del encabalgamiento, su lugar en el terreno de lo estilístico, o las dudas sobre la existencia, o no, de pausa, pueden encontrar una explicación en el plano teórico de los conceptos jakobsonianos explicados.

7 Lo que no ofrece dudas a Bello [1859:133] es la existencia siempre de pausa al final del verso: "La pausa menor [la que separa un verso de otro] se contenta con marcar las más - pequeñas subdivisiones del razonamiento; pero no se le permite sino de cuando en cuando desunir [subrayo] aquellos grupos naturales que forman como palabras compuestas en que el oído percibe un solo acento lleno".

8 Sobre el encabalgamiento en la métrica española, son fundamentales los trabajos de A. Quilis, que, entroncando con la concepción de Rafael de Balbín sobre este fenómeno, tratan el aspecto histórico y sistemático; su obra Estructura del encabalgamiento en la métrica española sigue siendo el mejor estudio de conjunto del problema. Prueba del interés por el encabalgamiento en la métrica española son otros trabajos, posteriores al de Quilis, en los que se tratan problemas relacionados con el fenómeno. Por ejemplo: Emilio Alarcos Llorach, 1967; Ramón Almela Pérez, 1981; A. de los Cobos, 1975; Ricardo Senabre, 1982; aparte de alusiones que puedan encontrarse en trabajos no dedicados exclusivamente al encabalgamiento. 
Por lo que se refiere a la definición del encabalgamiento, ésta no se presenta con perfiles tan nítidos que ayude de manera automática a la localización del fenómeno de manera inequívoca en todos los pasajes del poema, donde pueda darse, por parte de todos los receptores del mismo. En efecto, definir el encabalgamiento como el "fenómeno fundado en el desequilibrio entre verso y sintaxis" [Navarro Tomás, 1956:42], o como el "no coincidir el verso con una unidad de sentido" [Alarcos, 1966:102], es hacerlo de una manera tan general que se estaría autorizado a ver encabalgamiento entre todos los versos que componen un período sintáctico. Habría, por ejemplo, encabalgamiento entre todos los versos siguientes de Rosalía de Castro, por constituir un período completo:

A través del follaje perenne

que oír deja rumores extraños,

y entre un mar de ondulante verdura,

amorosa mansión de los pájaros,

desde mis ventanas veo

el templo que quise tanto'.

$Y$, sin embargo, si se tienen en cuenta los resultados de las investigaciones de Antonio Quilis, sólo habría encabalgamiento entre los dos primeros versos, por tratarse de una oración adjetiva especificativa [Quilis, 1969:79]. No puede extrañar el encontrar observaciones sobre una separación de elementos sintácticos vista como encabalgamiento $y$, sin embargo, tratarse de casos en que, de acuerdo con las investigaciones de A. Quilis, no hay tal encabalgamiento. Un ejemplo es el de Dámaso Alonso [1971:73], cuando comenta como caso de encabalgamiento los siguientes versos de Garcilaso:

Peinando sus cabellos de oro fino, una ninfa, del agua, do moraba, la cabeza sacó ${ }^{10}$.

9 En las orillas del Sar, Madrid, Castalia (Cl. Castalia, 90). 1976, p. 68.

10 Que es posible la pausa al final de cada uno de estos versos, lo demuestra el hecho de la existencia del signo ortográfico de la coma. Los versos de Garcilaso comentados por D. Alonso en la página 100 no presentan tantos casos de encabalgamiento como los señalados por el insigne crítico, si nos atenemos a los resultados de A. Quilis. Según éste, no hay encabalgamiento en la separación de verbo y complemento directo, y D. 
Todo esto se explica por el hecho de que, como dice Quilis [1964:79], refiriéndose a los preceptistas, "ninguno ha puesto mano a un estudio metódico de la estructura intrínseca".

¿Es posible una definición del encabalgamiento desde el punto de vista de la norma métrica, de las constantes métricas; o sólo será posible una definición desde el punto de vista de la recepción del poema? Mi opinión es que en el sistema métrico la norma general es que la pausa coincida con el límite de palabra" ; no hay normas métricas que prohíban separar sirremas. Puede haber (y las hay, sí) normas estilísticas que, en función de un modelo de ejecución más o menos cercano a la prosa literaria o a la lengua hablada, hagan sentir como más o menos violentas ciertas separaciones; separaciones que en una interpretación pura y exclusivamente rítmica no pueden extrañar. Por supuesto que las distintas escuelas pueden adoptar, por muy distintas razones o condicionamientos históricos (versos para ser leídos o para ser recitados en público, por ejemplo), distintos modelos estilísticos de relación entre el ritmo y la sintaxis. Las conclusiones a que llega Quilis [1965], en su estudio de la historia del encabalgamiento desde los orígenes hasta el siglo XVI, ilustran lo que acabo de decir: 1 . el encabalgamiento existe desde el principio; 2 . es propio de la poesía culta y no de la popular; 3. hasta el siglo XVI no empieza su uso como recurso expresivo.

Las elecciones de una escuela, en este terreno, pueden ilustrarse, igualmente, con las palabras de Lázaro Carreter [1972:17] cuando se-

\footnotetext{
Alonso, sin embargo, habla de encabalgamiento en "...traian/cestillos blancos de purpúreas rosas". Sería discutible, igualmente, el ejemplo de encabalgamiento comentado por Alarcos [1966:103] en los versos de Blas de Otero y consistente en la separación, en dos versos, de los distintos miembros de la enumeración: "Cuando morir es ir donde no hay nadie, / nadie, nadie; caer, no llegar nunca, / nunca, nunca; morirse y no poder / hablar, gritar, hacer la gran pregunta". Caso problemático es igualmente el de la separación de un sirrema por el hipérbaton. Alarcos [1966:107] forma un grupo especial de dislocación de la sintaxis con estos casos. Senabre [1982:42-43] considera que hay encabalgamiento, por separación de deseado y reposo, en los versos siguientes de Fray Luis: " $\mathrm{O}$ Oh ya seguro puerto / de mi tan luengo error! ¡Oh deseado / para reparo cierto / del grave mal pasado / reposo alegre, dulce, descansado!".

11 No estoy seguro de que esta afirmación de carácter general tenga un valor universal en la métrica castellana. En los versos compuestos pueden encontrarse casos en que el análisis métrico, el esquema de verso, exige la pausa en el interior de la palabra. Otra cuestión es que todos los lectores sean capaces de percibir esa norma. Pero se trata ya de un problema entre emisor y receptor; es esta una cuestión que tiene que sopesar el poeta cuando emite un ejemplo de verso que exige un modelo de ejecución sumamente rítmico, para ser percibido como perteneciente a un modelo de verso preciso. Ejemplo de lo que digo pueden ser algunos versos de Rubén Dario, agrupables en el modelo de verso del alejandrino. Quilis [1964:94-95] comenta dos ejemplos de Rubén Dario, que califica como casos de encabalgamiento léxico: "y tú paloma arru/lladora y montañera";
} 
ñala, como características del verso de arte mayor, "tendencia a la esticomitia, a la integridad del verso como unidad métrica y de sentido; equilibrio gramatical entre ambos hemistiquios y autonomía relativa de cada uno de ellos".

A. Quilis [1964:84], después de definir el encabalgamiento como "el desajuste que se produce en una pausa versal al no ser de ninguna manera pausa sintáctica", obra consecuentemente e investiga la sintaxis; así hay un terreno objetivo sobre el que empezar el estudio. Ahora bien, podría uno preguntarse si los resultados obtenidos a partir de la lectura que las personas cultas hacen de un texto en prosa pueden aplicarse automáticamente al verso. El verso se caracteriza por un tipo de segmentación peculiar (que puede, o no, coincidir con la sintáctica) y nadie puede negar el derecho a exigir un modelo de ejecución en que se hagan las pausas como las marca tal segmentación. Un modelo de ejecución rítmica -es decir, totalmente adaptado al tipo de segmentación del verso- no se extrañaría con cualquier separación que coincidiera con el final de palabra (e incluso acepta la separación de una palabra en el encabalgamiento léxico) ${ }^{12}$. Quilis, quien nos ha mostrado cómo estudiar las características de un modelo de ejecución determinado -el de la lectura de la prosa literaria hecha por personas cultas-, deja también la puerta abierta a las variables que dependen de la interpretación, cuando afirma que "el encabalgamiento es un fenómeno de orden objetivo que se da en unas condiciones gramaticales determinadas sin prejuicio, claro está, de lo que la interpretación, fenómeno subjetivo, pueda hacer resaltar" [1964:83].

No extraña que un estudioso del encabalgamiento como Ramón Almela, que no ignora los trabajos de Quilis, diga: "Los casos que presento se pueden considerar encabalgamientos en sentido lato. Para aquel que tenga un criterio más estricto, le bastará, para ser conse-

“ ¿Cuándo será la ca/bellera que se inclina". $M^{2}$ Josefa Canellada [1949] cita el siguiente verso, también de Rubén Dario: "Y el duelo de mi co/razón triste de espinas". Navarro Tomás [1959:35] comenta otros casos de Juan Ramón Jiménez.

12 El mismo Quilis [1964:56] manifiesta su deseo de "haber podido comprobar cuáles son los grupos inseparables en el lenguaje coloquial moderno", aunque piensa "que se puede ajustar más a la construcción sintáctica de la poesía, la de la prosa". Bello [1859:134135], por ejemplo, explica, a partir de la manifestación coloquial del lenguaje, la pausa tras que en los versos de Calderón: "Digo que me ha parecido/tan bien, Clara hermosa, que/ ha de pesarte algún día / que me parezca tan bien". Comenta Bello: "Esta práctica es un remedo de aquellos ligeros embarazos y suspensiones que ocurren a menudo cuando hablamos, y que diferencian casi siempre el razonamiento extemporáneo del estudiado. Así es que, empleada una que otra vez, no carece de gracia, sobre todo en el estilo familiar, que debe ser un trasunto de la conversación ordinaria". 
cuente, eliminar del cómputo los apartados que juzgue impropios" [1981:158].

La definición del encabalgamiento suele ser tan general que lo que hace es posponer los problemas a la hora de definir y precisar el caso concreto de desajuste entre pausas sintáctica y métrica. Y esto se debe a que es clara la peculiaridad, la libertad, de la segmentación rítmica. Pero, aunque no se pueda definir en los términos objetivos deseados el fenómeno, de lo que no hay duda es de su consideración como recurso estilístico de primer orden, al menos desde la introducción de la poesía italianizante en España. Quilis [1964:79] observa cómo los preceptistas vieron bien el valor estilístico, el matiz especial, del encabalgamiento ${ }^{13}$. Y en este terreno es en el que se han hecho las apreciaciones más valiosas. Muy atinadamente Navarro Tomás [1959:32-35] sitúa los problemas del encabalgamiento entre los complementos ritmicos, junto a hechos estilísticos que tienen que ver con la fonética rítmica (armonía vocálica, efecto evocativo) o la sintaxis rítmica (correlación, repercusión). En su Métrica Española, a la hora de caracterizar la versificación de las distintas épocas y escuelas, dedica un espacio a los complementos rítmicos también.

En el terreno de los estudios concretos, es obligatoria la referencia, en primer lugar, a Dámaso Alonso, quien nunca olvida la alusión al encabalgamiento cuando analiza la poesía de un autor. Sean ejemplo de lo que digo sus trabajos sobre Garcilaso, Medrano, Góngora, Antonio Machado o la "Epístola Moral a Fabio". Dámaso Alonso [1973-85: VIII,53-55] explica el encabalgamiento como procedimiento de intensificación del significado, y dice que "los encabalgamientos intensifican unas veces la suavidad y otras la aspereza o la pujanza o el esfuerzo (porque todo procede de lo que haya en el significado)". Hablando de un río, se intensifica la rapidez o la fuerza en los siguientes versos de la "Epístola Moral a Fabio":

Dejémosla pasar como a la fiera corriente del gran Betis, cuando airado dilata hasta los montes su ribera.

Y comenta Dámaso Alonso: "Hay algo en la fluencia, ya suave, ya violenta, de los ríos, que lleva como a pintarla, describirla, imaginativamente, por la fluencia, ya mansa o ya arrebatada del verso". El autor de la "Epístola Moral a Fabio" se deja llevar "por esa casi nece-

13 Para el siglo XIX, véase José Domínguez Caparrós, 1975: 275-294. 
sidad de trasponer el violento avance de un río al violento avance del verso". (Otras referencias de Dámaso Alonso al encabalgamiento pueden encontrarse en: 1971; 1973-85:III; VII,180-181; VIII, 638-639).

En la misma línea de relación entre el significado y el significante, es interpretado el encabalgamiento en la poesía de Blas de Otero por Emilio Alarcos Llorach [1966:100], cuando da como valor general de la falta de adecuación entre pausa métrica y pausa sintáctica el de una "impresión de violencia". También Ricardo Senabre [1982:44] pone en estrecha relación significante y significado en su interpretación de los encabalgamientos de Fray Luis de León, cuando dice: "Un buen número de encabalgamientos luisianos tiene como función esencial la de marcar una distancia, real o subjetiva, cronológica o espacial, entre dos nociones, sin descartar en ciertos casos otros efectos secundarios".

Basten estas muestras de cómo suele ser interpretado el encabalgamiento, y de cómo entra ya dentro de los fenómenos estilísticos que tienen que ser comentados al hablar de la poesía. Desde que se empezó a hablar del encabalgamiento, el aspecto estilístico es el menos discutido. Que el desajuste entre metro y sintaxis produce un efecto estilístico (reforzamiento del significado, violencia, distancia, etc...), es una apreciación comúnmente aceptada.

Menos claramente solucionada está la cuestión de si, en la lectura de los versos que están implicados en el encabalgamiento, debe hacerse siempre pausa entre el verso encabalgante y el encabalgado. Doy algunos ejemplos de posturas diferentes. Andrés Bello [1859:133,134] no duda de que siempre se haga una pausa al final del verso, la cual puede "de cuando en cuando desunir aquellos grupos naturales que forman como palabras compuestas en que el oído percibe un solo acento lleno"; también habla Bello de "la pausa con que debe señalarse el tránsito de un verso a otro". Dámaso Alonso [1971:68], comentando el pensamiento de Grammont en este punto, le da la razón sobre la existencia siempre de pausa al final del verso, "pero habría que decir que con el encabalgamiento es a veces brevísima". Alarcos Llorach [1966:103] habla también de que la pausa métrica, en caso de encabalgamiento, se hace lo más breve posible, pues "al encontrarse la secuencia sintáctica frenada por una pausa métrica, se tenderá a hacer ésta lo más breve posible, y pasar rápidamente al verso siguiente" ${ }^{*}$. María Josefa Canellada [1949] sostiene que el sentido es "el que vence en la lucha cuando se da el encabalgamiento". La unidad métrica del verso, al no estar marcada por la introducción de un tiempo respiratorio, es señalada entonces en la recitación por medio de la entonación y la

14 También Ricardo Senabre, de pasada, afirma la existencia de pausa siempre al final del verso: “... puesto que el final de verso obliga siempre a una suspensión, por leve que sea, en la fluencia del enunciado..." [1982:44]. 
rima, en los versos en que la hay. La conclusión de María Josefa Canellada, de todas formas, no puede ser más relativista, cuando dice que, dejando aparte el caso en que divide palabras, "el encabalgamiento responde siempre al criterio del recitante".

No muy alejada de ésta, en definitiva, está la posición que mantiene A. Quilis. En efecto, Quilis describe perfectamente el modelo de ejecución correspondiente al de la prosa literaria y lo aplica en sus análisis. Consecuentemente, no hará pausa en los casos de sirremas divididos en dos versos ${ }^{15}$. Pero no puede tampoco negar la posibilidad de que alguien haga la pausa en su recitación. Las dos posibilidades están apuntadas en la presentación general del problema en su Métrica Española: "Ya nos hemos referido antes al hecho de que cada verso requiere forzosamente una pausa; sin embargo, puede suceder que por razones morfosintácticas la realización de esa pausa obligada resulte violenta". Y más adelante: "La pausa y la rima constituyen el marco métrico del verso. Como en el encabalgamiento lo que sucede es que se anula la pausa versal, en la gran mayoría de los casos, ésta ya no sigue ejerciendo el oficio de compuerta cerrada al final del verso" [1969:79 y 86 $]^{16}$.

Sin haber agotado, ni mucho menos, la relación de distintos planteamientos del problema del encabalgamiento, creo que ya hay los elementos suficientes como para intentar un comentario de los puntos discutidos en el marco de los conceptos jakobsonianos.

15 Véase, por ejemplo, cómo explica el análisis del encabalgamiento entre los hemistiquios del alejandrino El primero es Gonzalo / de Berceo llamado: "El verso 1 presenta un encabalgamiento sirremático: Gonzalo // de Berceo. El dilema que se presenta es el que ya hemos señalado: si se mantiene la pausa, se rompe la unidad del sirrema; si se mantiene ésta, se viola la pausa. Nosotros hemos optado por la segunda solución" [1969:183; y también 174 y 191]. La solución adoptada supone elegir un modelo de ejecución que en este caso es el de la prosa literaria, en cuya lectura se fundamenta, precisamente, la definición de sirrema.

16 He subrayado yo. Giuseppe Tavani [1967:297-298] achaca a Quilis el sostener la postura de que siempre prevalece la sintaxis sobre la métrica. Pero no parece que esta sea exactamente la posición de Quilis, quien en su estudio del encabalgamiento analiza también encabalgamientos pausados; y siempre deja la posibilidad de una lectura con pausa, aunque él opte en sus análisis (explicando, además, que se trata de una opción) por la lectura sin pausa. Gian Luigi Beccaria [1975:13-14] comenta en têrminos muy elogiosos el trabajo de Quilis sobre el encabalgamiento, y le reprocha que no aclare si hay, o no, pausa al final del verso, sacando como conclusión que el problema del encabalgamiento no se resuelve en el plano de la ejecución: "La pur pregevole ed utile ricerca di Quilis non solo non è, a dispetto delle verifiche di laboratorio, molto chiara addirittura sull'esistenza o meno della pausa di fine verso (a volte Quilis sembra dire che la pausa metrica c'è, a volte negarla); ma ribadisce comunque che il problema dell'enjambement resta irrisolto quando ci si affida alla esecuzione di un lettore, perché il lettore ora sopprime la pausa, ora la esegue con lieve marcatura, ora risente delle abitudini scolastiche o personali e la conserva pesantemente". Yo no pienso, ni mucho menos, que el 
Por lo que se refiere a la definición, no puede extrañar que sea tan general, pues la norma métrica castellana -que, por supuesto, habría que diferenciar según las distintas épocas o escuelas- ha admitido hasta ahora una segmentación bastante independiente de la sintáctica. Llega a tolerar, en algunos casos (poesía jocosa, alejandrino usado por los modernistas), la segmentación rítmica en el interior de una palabra. A partir de aquí, una recepción totalmente rítmica del poema no puede extrañarse de esas divisiones, que incluso acentúan sílabas átonas interiores de palabra y les dan un valor de dos sílabas métricas. El encabalgamiento es, pues, un fenómeno de variación estilística que se sitúa en el ejemplo de verso concreto. Definirlo como desajuste entre metro y sintaxis es no decir nada métricamente peculiar, puesto que lo normativo es la originalidad de la segmentación rítmica, y, por tanto, tales desajustes son métricamente posibles. Por ser un fenómeno estilístico, goza de la misma falta de precisión que las definiciones de otros fenómenos estilísticos -por ejemplo, ¿cuántas veces tiene que repetirse el mismo sonido para que haya aliteración?-. El encabalgamiento, como fenómeno estilístico, será percibido solamente, no en contraste con una norma exclusivamente rítmica (porque, repito, la norma rítmica admite hasta la división de palabras), sino en contraste con un modelo de ejecución más o menos cercano a la prosa, al habla coloquial. Es decir, si funcionamos en nuestra recepción con los esquemas de la sintaxis de la prosa, sí nos llamará la atención el desajuste; pero, si lo hacemos con los esquemas de la segmentación rítmica, no nos llamará la atención. Lo que ocurre es que en la ejecución del poema se suele funcionar con los dos modelos a la vez, y de ahí la lucha, la duda entre sonido y sentido a que se refieren los comentaristas del encabalgamiento. Porque el poema es música, ritmo fónico, pero también comunicación de contenidos lingüísticos, con sus exigencias. Por eso, quienes dicen que en el encabalgamiento se hace siempre pausa tienen razón: están hablando de un ejemplo de ejecución ajustado al modelo de ejecución rítmica. Y, además, podrían decir que, si no se hace la pausa, se perdería precisamente el efecto estilístico, cifrado frecuentemente en la sorpresa, la desautomatización de sintagmas normales de la len-

estudio de la ejecución sea despreciable. Al contrario, nos enseñará bastante sobre la efectividad o no, y en qué grado, de las normas métricas, del éxito o no de la comunicación rítmica, o de las distintas actitudes ante el hecho rítmico. Dice Quilis [1964:127]: "El encabalgamiento se produce cuando por motivos sintácticos es preciso suprimir o casi [subrayo] anular la pausa versal"; y más adelante [1964:181]: "Cuando hemos hecho la pausa versal en el encabalgamiento [subrayo], se han mantenido en suspensión los dos elementos -finales e iniciales- de los versos afectados por el fenómeno...". Bien es verdad que en pág. 128 dice: "De igual manera, segün que la pausa versal que se suprima esté situada al final de un verso simple o en el interior de un verso compuesto, así el encabalgamiento recibirá el nombre de versal o de medial". 
gua. Quienes dicen que no se hace pausa están hablando de un ejemplo de ejecución fundado en un modelo de ejecución cercano a la sintaxis de la prosa. Y para ellos el efecto estilístico estaría, precisamente, en el contraste con los versos que se ajustan a la segmentación sintáctica.

La pausa, por supuesto, existe siempre en el modelo de verso y en el ejemplo de verso (los versos se definen por las pausas que dividen grupos de sílabas; $y$ el autor dispone los versos en entidades independientes). Dos preguntas importantísimas vienen enseguida a la mente: ¿hay modelos de ejecución que sean amétricos?, ¿cuántos modelos de ejecución métricos hay? Con la primera pregunta se relacionan las frecuentes observaciones acerca de la insatisfacción que producen las recitaciones de los versos del teatro clásico español; parece que si se adopta un modelo de ejecución que da la mayor importancia al esquema rítmico, se cae en el sonsonete demasiado perceptible; mientras que la recitación muy apegada al sentido produce la sensación de que el verso es destruido, es prosa. ¿Cómo solucionar el problema? Una vía de acercamiento a la solución sería el análisis de las ejecuciones de los mismos que escriben los versos. Se sabría, así, algo de cómo piensan que deben ser interpretadas sus obras los mismos que las escriben. A partir de esos análisis -y de los análisis de las interpretaciones de personas acostumbradas a leer versos- podrían establecerse los distintos modelos de ejecución métricos. Si los modelos de ejecución son muy variados, o si se pueden reducir a dos tendencias (no natural, ritmizante, por un lado; y tendencia a seguir la frase, lectura natural, agrupadora, en que prevalece el interés por el contenido, por otro lado, como quiere Gian Luigi Beccaria [1975:15]), es una cuestión que podrá responderse mejor después de los análisis de muchos ejemplos de ejecución.

Dentro de esta serie de problemas, se comprende también que María Josefa Canellada diga, según se ha visto, que el encabalgamiento "responde siempre al criterio del recitante"; es decir, es un problema de modelo y ejemplo de ejecución". Aunque deja aparte el caso de los encabalgamientos léxicos. Veamos los siguientes versos de Rubén Darío:

\section{Al lado izquierdo del camino y paralela- mente, siete mancebos -oro, seda, escarlata, armas ricas de Oriente-hermosos, parecidos}

17 Jakobson [1960: 367 de la edición en inglés] ilustra el concepto de ejemplo de ejecución con un caso de encabalgamiento, pues comenta las posibles recitaciones de los versos de Hopkins: "But tell me, child, your choice; what shall 1 buy / You? - Father, what you buy me I like best". 


\begin{abstract}
a los satanes verlenianos de Ecbatana, vienen también. Sus labios sensuales y encendidos, de efebos criminales, son cual rosas sangrientas ${ }^{18}$.
\end{abstract}

Estos versos, sacados del interior de un poema en alejandrinos, ¿serían interpretados métricamente bien si no se hace pausa tras del (v.1) y se cuenta como dos sílabas métricas, o tras la sílaba ver de verlenianos (v.4), que también cuenta como dos'sílabas métricas? ¿Vale en estos casos la lectura natural, opuesta a la rítmica, que haría esas pausas?

Como vemos, no está agotado el campo de la investigación métrica, y todavía hay preguntas que esperan una respuesta que proceda de los resultados de una investigación de la pragmática, de la relación del lector con el poema. Los conceptos teóricos formulados por Jakobson pueden hacernos avanzar en el sentido de colocar los problemas y sus respuestas en el sitio adecuado. El encabalgamiento se sitúa en el lugar de las variables, de lo estilístico, en el juego con los hábitos receptivos. Hábitos que el emisor, el poeta, tiene muy en cuenta, por supuesto, en función de su intención expresiva.

\title{
Bibliografia CITADA
}

Alarcos Llorach, Emilio, 1966: La poesía de Blas de Otero. Salamanca, Anaya, 1973, 2 edición.

__ 1967: "Secuencia sintáctica y secuencia rítmica", en Ensayos y estudios literarios. Madrid, Júcar, 1976, 237-242.

Almela Perez, Ramón, 1981: "Formas de encabalgamiento en Pedro Salinas", en Revista de Literatura (Madrid), 43, n० 85, 155-165.

Alonso, Dámaso, 1971: Poesia Española. Madrid, Gredos, 5“ edjción.

_ 1973-1985: Obras Completas. Madrid, Gredos, vols. II-VIII.

Beaver, Joseph C., 1974: "Generative metrics: The present outlook" en Poetics (The Hague), 12, 7-28.

BeCCARIA, Gian Luigi, 1975: L'autonomia del significante. Figure del ritmo e della sintassi. Dante, Pascoli, D'Annunzio. Torino, Einaudi.

BELIC, Oldfich, 1975: En busca del verso español. Praha, Univerzita Karlova.

Bello, Andrés, 1859: Principios de la Ortología y Métrica de la Lengua Castellana, en Obras Completas. Caracas, La Casa de Bello, Tomo VI, 1981.

Brik, Osip, 1927: "Rythme et syntaxe", en Todorov, T. (ed.). Theorie de la litrérature. Paris, Seuil, 1965, 143-153.

CANElladA, María Josefa, 1949: "Encabalgamiento", en AA.VV.. Diccionario de Lireratura Española. Madrid, Revista de Occidente. 1972. $4^{2}$ edición corregida y aumentada.

18 Del poema "El reino interior", en Poesia, Introducción y selección de Jorge Campos, Madrid, Alianza Editorial, 1977, pág. 65. 
CoBos, A. de los, 1975: "Notas para el estudio sintagmático del encabalgamiento", en Mélanges offerts à Charles Vincent Aubrun. Paris, Editions Hispaniques, vol. I, 201212.

Cornulier, Benoit de, 1982: Théorie du vers. Paris, Seuil.

Dominguez Caparros, José, 1975: Contribución a la historia de las teorias métricas en los siglos XVIII y XIX. Madrid, CSIC.

1985: Diccionario de métrica española. Madrid, Paraninfo.

Fubini, Mario, 1962: Metrica y Poesía. Barcelona, Planeta, 1970.

Girolamo, Costanzo di, 1983: Teoría e prassi della versificazione. Bologna, Il Mulino, $2^{4}$ ed. revisada.

GUERON, Jacqueline, 1974: "The Meter of Nursery Rhymes: An Application of the HalleKeyser Theory of Meter", en Poetics (The Hague), 12, 73-111.

Halle, Morris, 1970: "On Meter and Prosody", en Manfred Bierwisch and Karl Erich Heidolph (eds.), Progress in Linguistics: A Collection of Papers, Janua Linguarum Major Series, XLIII, The Hague, Mouton, 64-80.

Hernandez Vista, V. Eugenio, 1972: "Ritmo, metro y sentido", en Prohemio (Madrid), 3, 93-107.

Hrushovski, Benjamin, 1960: "On Free Rhythms in Modern Poetry", en Thomas A. Sebeok (ed.) 1960:173-190.

IHwE, Jens F., 1975: "On the Foundations of 'Generative Metrics", en Poetics (The Hague), 16, 367-399.

JaCQuiER, H., 1970: "Métrique traditionnelle et métrique zéro", en Actes du Xe Congrès des Linguistes (1967), Bucarest, III, 121-125.

JakOBSON, Roman, 1960: "Closing statements: Linguistics and Poetics", en Thomas Sebeok (ed.) 1960, 350-377. Trad. francesa: "Linguistique et poétique", en Essais de linguistique générale. Paris, Minuit, 1963, 209-248. Cito por la traducción francesa.

lazaro CarReter, Fernando, 1972: "La poética del arte mayor castellano", en Estudios de Poética. (La obra en si). Madrid, Taurus, 1976, 75-111.

LUQUe MORENO, Jesús, 1984: "Niveles de análisis en el lenguaje versificado", en Athlon. Satura grammatica in honorem Francisci R. Adrados. Madrid, Gredos, vol. I, 287-299.

MARINER BigorRa, Sebastián, 1971: "Hacia una métrica estructural", en Revista Española de Lingüistica (Madrid), I, 299-333.

Navarro Tomás, Tomás, 1956: Métrica española. Madrịd, Guadarrama, 1972.

1959: Arte del verso. México, Colección Málaga, 1968, $4^{2}$ edic.

Nelson, Lowry, Jr. 1972: "Spanish", en Wimsatt, W. K. (ed), Versificacion: Major Language Types. New York, N. Y. University Press, 165-176.

Quilis Morales, Antonio, 1964: Estructura del encabalgamiento en la métrica española. (Contribución a su estudio experimental). Madrid, CSIC.

- 1965: "El encabalgamiento desde los orígenes de la poesía española hasta el siglo XvI", en Actes du Xe Congrès International de Linguistique et Philologie Romanes, Strasbourg, 1962. Paris, 791-813.

1969: Métrica española. Barcelona, Ariel, 1984, 1 * edición corregida y aumentada.

SaAvedra Molina, Julio, 1945: El octosilabo castellano. Santiago de Chile, Prensas de la Universidad de Chile.

1950: "Teoría del poema", en Boletin de Filología (Santiago de Chile), VI, 1950$51,25-252$.

SEBEOK, Thomas A. (ed.), 1960: Style in Language. Cambridge (Massachussets), First MIT Press Paperback Edition, 1966.

Senabre Sempere, Ricardo, 1982: "El encabalgamiento en la poesía de Fray Luis de Leơn", en Revista de Filologia Española (Madrid), 62, 39-49.

TavaNI, Giuseppe, 1967: Sobre Quilis, 1964, en Cultura Neolatina (Roma), 25, 297-298.

Tinianov, Iuri, 1924: El problema de la lengua poética. Buenos Aires, Siglo XXI, 1972.

TOMACHEVSKI, Boris, 1928: Teoria de la literatura. Madrid, Akal, 1982. 1929: "Sur le vers", en Todorov, T. (ed.), Théorie de la littérature. Paris, Seuil, $1965,154-169$.

ZIRMUNSKIJ, V., 1925: Introduction to metrics. The theory of verse. The Hague, Mouton, 1966 . 